\title{
Research on intelligent operation and maintenance management technology based on Microgrid group
}

\author{
Wu $\operatorname{Min}^{\mathrm{a}}$ \\ Tibet Autonomous Region Energy Research Demonstration Center, Lasa 850000, China
}

\begin{abstract}
In this paper, the research and platform development of cloud based microgrid cluster operation and maintenance management technology are carried out in Tibet, the solar thermal power combined microgrid system is built at decentralized load points, the data of each independent new energy system is integrated and shared by using Internet technology, and the unified operation, maintenance, monitoring and management of microgrid cluster are realized through the cloud platform, It can greatly improve the use efficiency of clean energy, improve the power supply quality and reliability of users, reduce the operation and maintenance cost, improve the work efficiency and system operation reliability, realize the intelligent monitoring, operation and maintenance and management of photovoltaic power generation and micro electric network group, and provide new operation and maintenance management methods and development ideas for the multi energy complementary and comprehensive utilization of Tibet Autonomous Region.
\end{abstract}

Keywords: Tibet region; Solar energy utilization; Microgrid group; Intelligent operation and maintenance

\section{Introduction}

Although Tibet has made outstanding achievements in the development and utilization of solar energy, through investigation, investigation and consultation, it is found that there is still a lack of real-time monitoring, management, analysis and statistics on the many photovoltaic power stations built and distributed in the whole region in Tibet. In addition, due to the lack of timely and effective power station operation and maintenance due to the sparsely populated area, extreme climate and traffic interruption, the operation status of the power station has been changed "Small problem" becomes "big fault", the maintenance of the failed photovoltaic power station was delayed due to the failure of timely and effective solution, and finally the function of the power station was continuously weakened to complete loss. The lack of energy supply made the already difficult living conditions of residents in agricultural and pastoral areas even worse and extremely difficult. In addition, the people's increased energy consumption and practical needs such as pleasant and livable, environmental protection and energy conservation brought about by the improvement of living conditions made them unnecessary or reduced The solar photothermal photoelectric technology and system with the characteristics of less external power input, promoting the coupling development of new energy use and economy, giving full play to Tibet's advantageous solar resources and integrating power supply + heating is an effective way to solve the power consumption problems of people in areas where the power grid cannot cover and areas with unstable power supply, meet the power demand, and take into account the future development trend Good layout[1].

The future of Tibet's new energy development must be inseparable from innovative measures in improving quality and efficiency, and later management and monitoring is an effective means. Therefore, the energy research and demonstration center of Tibet Autonomous Region has carried out relevant research work many years ago[2]. In 2014, the energy research and demonstration center of Tibet Autonomous region was launched in cooperation with Chongqing Institute of green intelligent technology, Chinese Academy of Sciences "Distributed solar power plant monitoring system" In the project, by building a remote monitoring and acquisition platform for photovoltaic power station data, remote monitoring is realized for the three photovoltaic power stations selected in Lhasa City, Naqu area and Yangbajing. By monitoring the output and input current, voltage and actual power of photovoltaic power stations, as well as the operation of batteries, inverters and photovoltaic modules, the daily power generation and input power of photovoltaic power stations are collected And monitoring of power consumption at the user's side. Although certain achievements have been made in the monitoring and management of photovoltaic power plants through continuous exploration and attempts, due to the technical limitations and actual conditions at that time, we still failed to realize data sharing and intelligent unified dispatching management among new energy power

a 853969982@qq.com 
generation systems, let alone carry out tasks such as load forecasting and dispatching based on big data analysis technology Exploration of advanced applications such as power generation prediction and Microgrid energy optimal dispatching[3].

To sum up: in order to adapt to the natural conditions of sparse population and harsh environment in Tibet, and in view of the current situation that various photovoltaic power stations are located in remote and remote areas, the local people's technical and cultural level is relatively low, and it is difficult to conduct on-site operation, maintenance and management, the project plans to develop and build a set of intelligent operation and management system of distributed generation and Microgrid system based on Cloud Architecture application. After completion, the system can support multiple distributed generation systems (such as distributed photovoltaic power generation system) and Microgrid systems to access wirelessly or wirelessly, realize data sharing and intelligent unified dispatching management between distributed generation systems and Microgrid, reduce operation and maintenance costs and reduce operation risks; Solar distributed power generation and heating system have the advantages of clean and environmental protection, but also have the disadvantages of volatility and uncontrollability. Based on big data analysis technology, the project carries out advanced applications such as load forecasting, power generation forecasting and Microgrid energy optimal dispatching, which can realize one site, one microgrid, multi-point layout, multi-point interconnection and energy exchange. In addition, in order to test the effectiveness of the intelligent operation and maintenance management platform of the microgrid group and explore a new mode of green heating and power supply in Tibet, the project will also make full use of solar energy supply (solar heating and heating, solar power generation), energy storage technology, thermoelectric microgrid energy interconnection management and other technologies through technological integration and innovation to develop a thermoelectric microgrid system in line with the energy consumption characteristics of Tibet, Provide new operation and maintenance management methods and development ideas for the comprehensive utilization of solar energy in the region, and become a strong scientific and technological support for practicing the concept of green and low-carbon economic development, promoting the improvement of people's livelihood, protecting ecology, strengthening "stabilizing Tibet by science and technology, enriching the people and strengthening the county by science and technology, targeted poverty alleviation by science and technology", and building a beautiful Tibet.

\section{Content of the project}

\subsection{Project overview}

In this paper, the project has carried out research on Intelligent interconnection management technology of unified information monitoring cloud platform based on big data analysis, and developed an intelligent operation and maintenance management platform of microgrid group based on cloud platform application, so that it can support multiple new energy systems (cogeneration microgrid system, wind solar complementary power station, photovoltaic power station, photothermal system and air source heat pump system) And Microgrid system are connected in wireless or wired mode, so as to achieve the purpose of data sharing and intelligent unified dispatching management between various photovoltaic power generation systems and Microgrid, and realize big data analysis technology to carry out advanced applications such as load forecasting, power generation forecasting, microgrid energy optimal dispatching and so on. In addition, in order to test the effectiveness of the intelligent operation and maintenance management platform of microgrid group and explore a new mode of green heating and power supply in Tibet, the project will also make full use of technologies such as solar energy supply (solar heating, solar power generation) energy storage technology and Microgrid energy interconnection management for combined heat and power through technological integration and innovation, A thermoelectric microgrid system in line with the energy consumption characteristics of Tibet has been developed to verify the performance of the platform together with the existing new energy facilities (wind solar complementary power station, photovoltaic power station, photothermal system and air source heat pump system), so as to provide new operation and maintenance management methods and development ideas for the comprehensive utilization of multi energy in the whole region. As shown in Figures 1 and 2, the project in this paper is located at No. 22 anjuyuan, Lhasa City, and the total charging capacity and discharge capacity from September 1 to September 8.

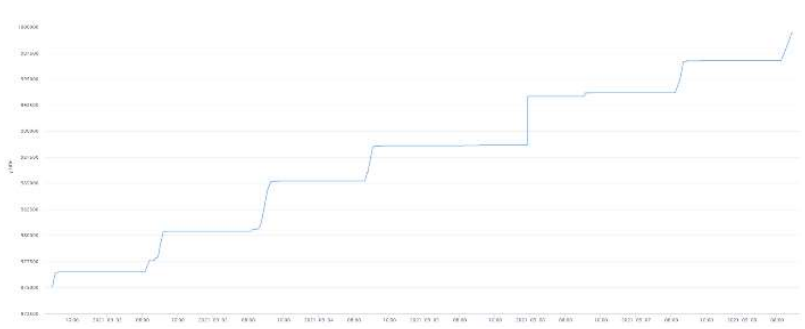

Fig.1 Total charge from September 1 to September 8

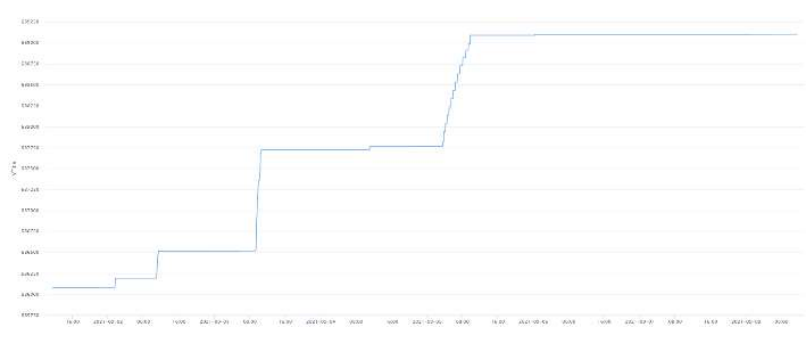

Fig.2 Total discharge from September 1 to September 8 


\subsection{Specific construction contents}

In March 2021, four representative project implementation sites with different energy demand and climate were located in maker space of the testing center of the energy research demonstration center of Tibet Autonomous Region, anjuyuan No. 22 of Lhasa Tibetan Medical College, the duty room of the township government of wumatang Township, Dangxiong County, Lhasa City, and the village Committee of Jirong village, zaxigang Township, Razi County, Shigatse City, A distributed cogeneration microgrid system with solar energy guarantee rate of no less than $50 \%$ has been built (including 1 set of $4 \mathrm{kWp}$ photovoltaic power generation system, 1 set of $12 \mathrm{kWh}$ energy storage system, 1 set of optical storage integrated machine with output power of $5 \mathrm{~kW}$ and air energy heat pump with total power of $5.5 \mathrm{~kW}$, $4.96 \mathrm{~kW}, 4.54 \mathrm{~kW}$ and $3.3 \mathrm{~kW}$ respectively). Through the above equipment, combined with the existing projects in Naqu and Ali demonstration sites, it is verified that the micro network group intelligent operation and maintenance management platform developed by the project carries out the research and demonstration of micro network energy consumption management, prediction, monitoring, operation and maintenance analysis and intelligent regulation of photoelectric, photothermal, storage and load integration. Figure 3-6 shows the real-time data of the projects involved in this paper.

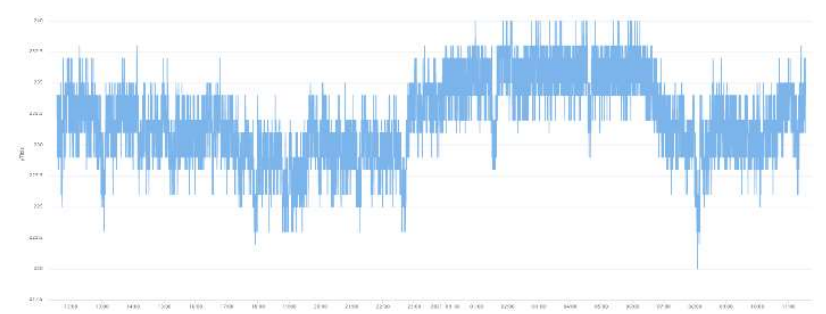

Fig. 3 Real time input voltage

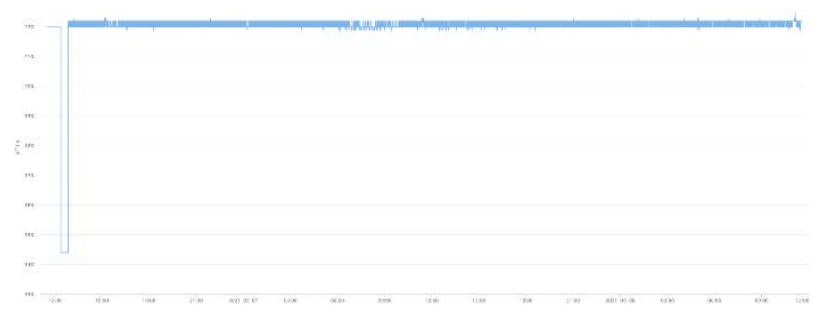

Fig.4 Real time output voltage

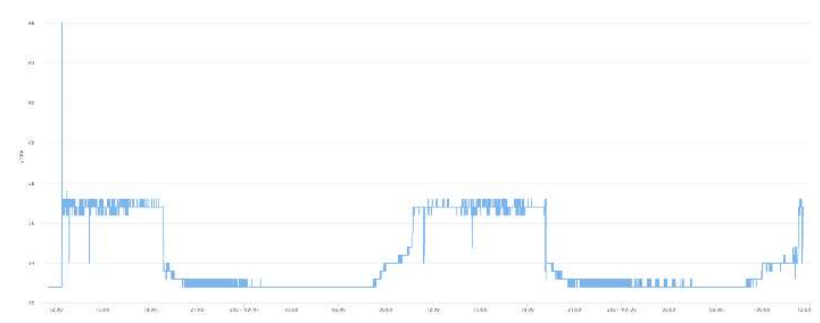

Fig.5 Real time battery voltage

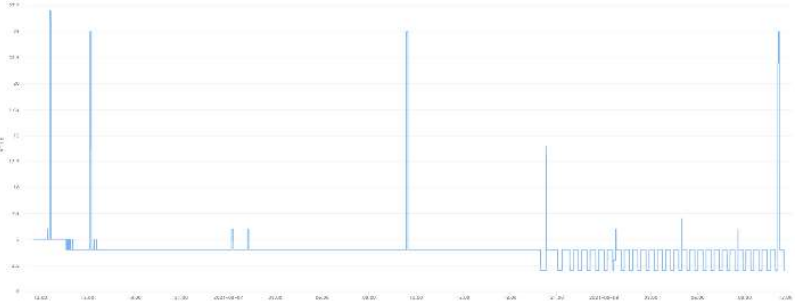

Fig.6 Load percentage from September 1 to September 8

\section{Benefit analysis}

Through the research of the project technology and the construction of the system in this paper, intelligent monitoring, operation and maintenance can be carried out for all kinds of photovoltaic power stations in Tibet and the power generation systems such as newly-built distributed power stations, microgrid systems and independent photovoltaic power stations, so as to improve the operation reliability of the connected power generation system, reduce the operation and maintenance cost, reduce the operation risk and reduce the maintenance cycle, Considerable economic benefits will be achieved. In addition, the existing photovoltaic power stations used to solve the power consumption of the masses and government organs are mainly invested by the state. The implementation of the project in this paper can avoid the idleness and waste of state-owned assets to a certain extent. In addition, according to the calculation of the average solar radiation in Lhasa, the cumulative installed capacity of the distributed photovoltaic microgrid system is not less than $16 \mathrm{~kW}$. The average daily power generation of the distributed photovoltaic microgrid system is about $85.3 \mathrm{kWh}$ and the annual average power generation is about $31134.5 \mathrm{kWh}$. According to the calculation of 0.7 yuan per kilowatt hour, the direct economic benefit is more than 21000 yuan per year. Coupled with the regulation of energy storage system, combined with air energy heat pump and energy consumption regulation, it not only solves the problem of power consumption, but also solves the problem of hot water heating.

The ecological status of Tibet Plateau is very important and it is an important ecological security barrier in China and even Asia. After the implementation of the project in this paper, it can make all kinds of photovoltaic power stations lacking management and maintenance operate normally for a long time, improve the reliability of power stations and reduce the use of conventional energy, which will certainly make greater contributions to reducing pollutant emissions and protecting the ecological environment of Tibet. In addition, the direct environmental benefits brought by the implementation of the project in this paper are equivalent to saving 11.2 tons of standard coal per year, reducing 8.45 tons of pollution dust, 31.01 tons of carbon dioxide, 0.93 tons of sulfur dioxide and 0.47 tons of nitrogen oxides. 


\section{Conclusion}

At present, after the overall completion of the project in March 2021, after four months of trial operation, the project in this paper runs in good condition, and all functions meet the user's requirements. Give full play to the intelligent monitoring, operation and maintenance and management of photovoltaic power generation and micro grid group, and play the established goal of improving the operation reliability of micro grid system, reducing operation and maintenance cost and reducing operation risk. Through the implementation of the project, the problems of power and heating in the duty room of wumatang township government in Dangxiong county and the village committee of Jirong village, zhaxigang Township, Shigatse have been effectively solved. According to the characteristics of high altitude and cold climate in Tibet, a number of scientific research projects in the field of solar energy that adapt to the plateau environment, can be replicated, have good effects and can be popularized and applied in the whole region have been built, Provide strong scientific and technological support for the high-quality economic and social development of the region, help industrial development and promote rural revitalization.

\section{Acknowledgments}

Research and platform development of micro network group intelligent operation and maintenance management technology based on Cloud Architecture (XZ202001YD0009C).

\section{References}

1. Zhang Feng, Zhang Jianhua. Research status and application prospect of smart microgrid [J]. Science and technology and enterprises. 2013 (14): 116.

2. Peng $\mathrm{C} \mathrm{H}$, Xie $\mathrm{P}$, Pan L, et al. Flexible robust optimization dispatch for hybrid wind/photovoltaic/hydro/thermal power .

3. Kaufmann M, Tüysüz A, Kolar J W. New optimum modulation of three-phase ZVS triangular current mode GaN inverter ensuring limited switching frequency variation[A]. 8th IET International Conference on Power Electronics, Machines and Drives (PEMD 2016)[C]. Glasgow, 2016. 